\title{
Genetic variants affecting incretin sensitivity and incretin secretion
}

\author{
K. Müssig • H. Staiger • F. Machicao • H.-U. Häring • \\ A. Fritsche
}

Received: 12 May 2010 / Accepted: 13 July 2010/Published online: 17 August 2010

(C) Springer-Verlag 2010

\begin{abstract}
Recent genome-wide association studies identified several novel risk genes for type 2 diabetes. The majority of these type 2 diabetes risk variants confer impaired pancreatic beta cell function. Though the molecular mechanisms by which common genetic variation within these loci affects beta cell function are not completely understood, risk variants may alter glucose-stimulated insulin secretion, proinsulin conversion, and incretin signals. In humans, the incretin effect is mediated by the secretion and insulinotropic action of two peptide hormones, glucose-dependent insulinotropic polypeptide and glucagon-like peptide-1. This review article aims to give an overview of the type 2 diabetes risk loci that were found to associate with incretin secretion or incretin action, paying special attention to the potential underlying mechanisms.
\end{abstract}

Keywords Diabetes mellitus type 2 - GIPR - Glucagon-like peptide-1 - Glucose-dependent insulinotropic peptide . Insulin secretion $\cdot K C N Q 1$ - Pancreatic beta cell $\cdot$ Review . TCF7L2 WFS1

\begin{tabular}{|c|c|}
\hline \multicolumn{2}{|c|}{ Abbreviations } \\
\hline GIP & Glucose-dependent insulinotropic peptide \\
\hline GIPR & GIP receptor \\
\hline GLP-1 & Glucagon-like peptide-1 \\
\hline GLP-1R & GLP-1 receptor \\
\hline KCNQ1 & $\begin{array}{l}\text { Potassium voltage-gated channel, KQT-like } \\
\text { subfamily, member } 1\end{array}$ \\
\hline
\end{tabular}

K. Müssig $\cdot$ H. Staiger $\cdot$ F. Machicao $\cdot$ H.-U. Häring $\cdot$

A. Fritsche $(\bowtie)$

Division of Endocrinology, Diabetology, Angiology,

Nephrology and Clinical Chemistry,

Department of Internal Medicine, Eberhard Karls University,

Member of the German Centre for Diabetes Research (DZD),

Otfried-Müller-Strasse 10,

72076 Tübingen, Germany

e-mail: andreas.fritsche@med.uni-tuebingen.de
MTNR1B Melatonin receptor 1B

TCF7L2 Transcription factor 7-like 2

WFS Wolfram syndrome

WNT Wingless-type MMTV integration site family member 2

ZnT-8 Zinc transporter 8

\section{Introduction}

As a result of the dramatic increase in the incidence of type 2 diabetes mellitus worldwide, this chronic and progressive disease has reached epidemic proportions with major health consequences at an individual as well as a public health level [1]. Impaired pancreatic beta cell function as well as central and peripheral insulin resistance are key features in the pathophysiology of type 2 diabetes mellitus [2]. The most relevant environmental factors in the development of type 2 diabetes comprise excessive energy intake and reduced physical activity on the background of a genetic predisposition [3].

Recent genome-wide association studies identified a series of novel type 2 diabetes risk loci [4-15]. The majority of these type 2 diabetes risk variants confer an impaired pancreatic beta cell function $[8,14-37]$. Though the underlying mechanisms by which common genetic variation within these loci affects beta cell function are not completely understood, risk variants may alter glucose-stimulated insulin secretion [16, 17, 19, 24, 25, 30, 32], proinsulin conversion $[21,38-40]$ and incretin secretion or incretin action.

\section{Effects of type 2 diabetes risk variants on incretin secretion and incretin action}

The two major incretins glucagon-like peptide 1 (GLP-1) and glucose-dependent insulinotropic peptide (GIP), for- 
merly known as gastric inhibitory peptide, which account for up to $60 \%$ of postprandial insulin release in healthy people, are secreted in response to meals by the $\mathrm{L}$ cells of the distal ileum and colon and the $\mathrm{K}$ cells of the duodenum and jejunum, respectively (for review, see Holst et al. [41]). The biologically active forms of GLP-1, i.e. GLP-1 $1_{(7-36)}$ amide and GLP-1 $1_{(7-37)}$, and GIP are derived from posttranslational processing of their precursors pro-GIP and proglucagon, respectively. As a result of rapid inactivation by the ubiquitously produced enzyme dipeptidyl peptidase-4, circulating incretins have a short duration of action. Both incretins act via specific receptors, i.e. the GLP-1 receptor (GLP-1R) and the GIP receptor (GIPR), respectively, both of which are members of the seven-transmembrane spanning, heterotrimeric G-protein-coupled receptor superfamily. The GLP-1R is produced in pancreatic alpha and beta cells as well as in heart, central nervous system, kidney, lung and gastrointestinal tract, whereas the GIPR is mainly found in pancreatic beta cells and, to a lesser extent, in the central nervous system, adipose tissue and osteoblasts. Metabolic actions of incretins comprise glucose-dependent insulin secretion, pancreatic beta cell proliferation, inhibition of beta cell apoptosis, and deceleration of gastric emptying. In addition, GLP-1 suppresses glucose-dependent glucagon secretion, appetite and food intake. In pancreatic beta cells, activation of the GLP-1R causes, through a stimulatory G-protein, production of the second messenger cyclic AMP, which mediates most of the GLP-1-dependent actions, including regulation of ion channel activity, intracellular calcium increase, insulin granule release, and insulin gene expression. Protein kinase A (PKA), the cyclic AMPregulated guanine nucleotide exchange factor II (cAMPGEFII, also known as EPAC2), as well as the cross-talk between PKA and the wingless-type MMTV integration site family member 2 (WNT) signalling pathway are involved in the aforementioned cyclic AMP-stimulated events (Fig. 1).

GLP-1 and GIP are the two major incretins accounting for up to $60 \%$ of postprandial insulin release in healthy people

As suggested by the production of GLP-1R and GIPR in multiple organs outside the pancreas, incretin actions are not limited to pancreatic islet cells, but they play regulatory roles in distinct tissues. While GLP-1 appears to promote beneficial effects on the cardiovascular system and central nervous system, the extrapancreatic actions of GIP comprise adipocyte function and fat storage as well as bone formation through stimulation of osteoblast proliferation and inhibition of apoptosis.
In type 2 diabetes, the incretin effect is impaired, with the insulinotropic action of GLP-1 being significantly more conserved than that of GIP. Though in some studies, postprandial concentrations of GLP-1 and GIP were diminished, the contribution of the potentially altered incretin secretion to the development of type 2 diabetes remains obscure [42]. In light of the described incretin actions in health and disease, genes encoding for proteins with impact on incretin production and secretion or on incretin signalling pathways appear to be potential type 2 diabetes candidate genes. In accordance with this assumption, some of the recently identified type 2 diabetes risk alleles appear to affect incretin secretion and incretin action (Table 1).

Genetic variants of TCF7L2 are associated most consistently with alterations in the incretin function. TCF $7 L 2$ encodes the transcription factor 7-like 2 (TCF7L2), which mediates the WNT signalling pathway [43]. The latter has been reported to be involved in the neonatal regulation of normal and regenerative growth of pancreatic beta cells [44]. Heterodimerisation of TCF7L2 with $\beta$-catenin results in transcription of numerous genes, such as that for proglucagon, which is processed to GLP-1 in the intestinal L cells [45]. GLP-1, which exhibits a wide range of glucose-lowering actions [43], stimulates pancreatic beta cell proliferation through activation of the WNT signalling pathway [46]. Positive feedback between GLP-1 and WNT signalling enhances the beneficial effects of GLP-1 on pancreatic beta cell function [47]. Also the insulin gene appears to be a direct target of TCF7L2, given that the expression of the insulin gene was reported to correlate strongly with $T C F 7 L 2$ expression and to be diminished after targeted silencing of the TCF7L2 gene [48, 49]. In patients with type 2 diabetes, as well as in animal models of type 2 diabetes, TCF7L2 mRNA levels were found to be increased several-fold, whereas protein levels were decreased [49, 50]. Experimental knockdown of TCF7L2 by RNA interference in human and murine islets resulted in an increase in beta cell apoptosis as well as in a decrease in beta cell proliferation and glucose-stimulated insulin secretion [51]. The impairment of glucose-stimulated and incretinstimulated insulin secretion after TCF7L2 gene silencing was accompanied by a decrease in production of the GLP-1R and the GIPR as well as by an attenuation of the GLP-1-stimulated and GIP-stimulated AKT phosphorylation, and AKT-mediated forkhead box O1 (FOXO-1) phosphorylation and nuclear exclusion. A comparable reduction in GLP-1R and GIPR levels was also detected in islets from patients with type 2 diabetes [49]. Furthermore, reducing TCF7L2 levels by RNA interference decreased expression of beta cell genes regulating secretory granule fusion, such as Munc18-1 (also known as STXBP1) and ZnT-8 (also known as SLC30A8), resulting in defective insulin exocytosis [52]. In contrast, overexpression 


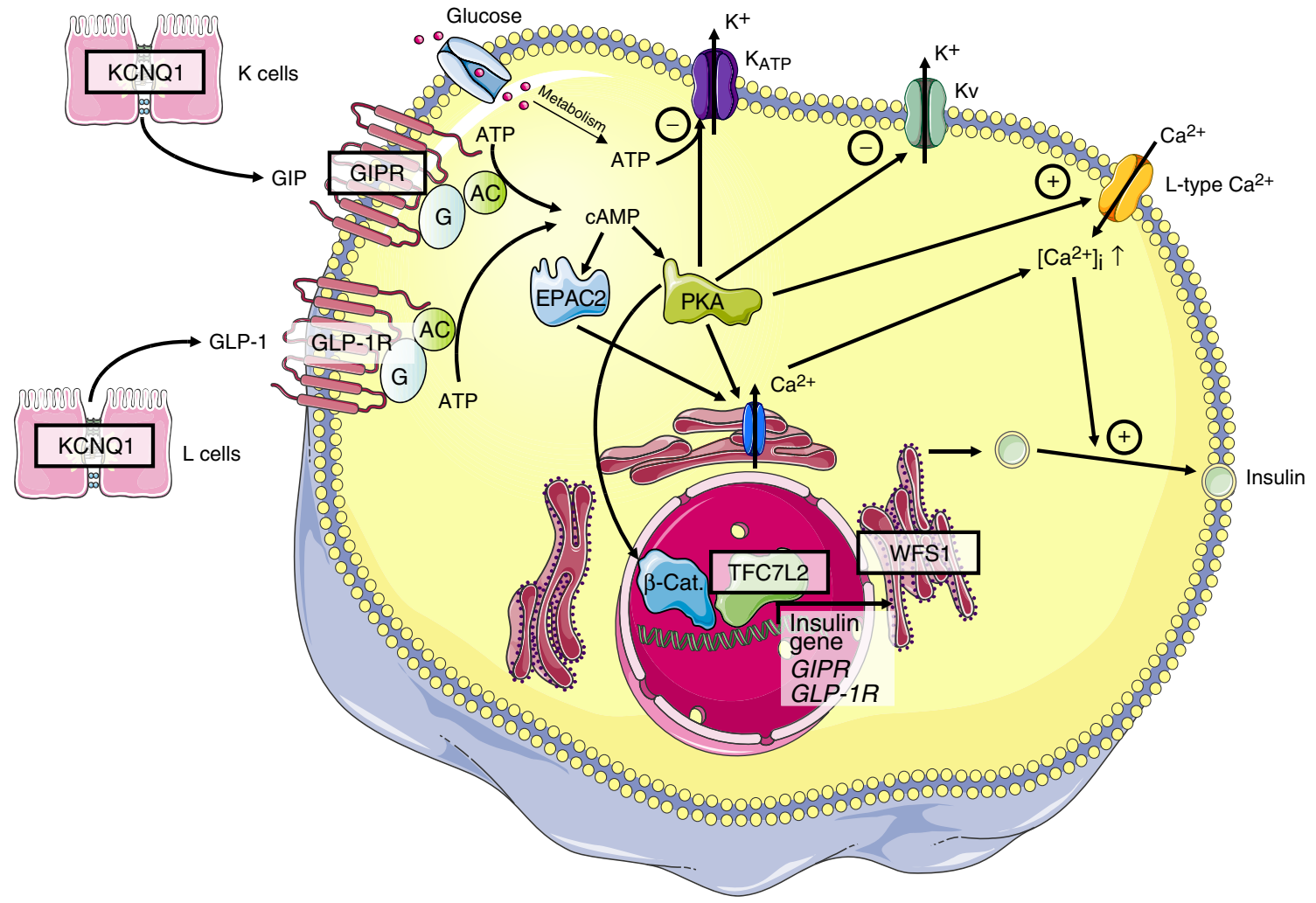

Fig. 1 Insulinotropic actions of GLP-1 and GIP in pancreatic beta cells. Binding of GLP-1 and GIP to their specific receptors, i.e. GLP$1 R$ and GIPR, causes, through a stimulatory G-protein $(G)$, activation of adenylyl cyclase (AC), which converts ATP into the second messenger cyclic AMP (cAMP). Increase of intracellular cAMP levels results in activation of protein kinase A (PKA) and the cAMPregulated guanine nucleotide exchange factor II (cAMP-GEFII, also known as EPAC2), which mediate most of the incretin-dependent actions. Synergistically with an increase in intracellular ATP levels, PKA-mediated phosphorylation of the ATP-sensitive potassium $\left(\mathrm{K}_{\text {АTP }}\right)$ channel leads to closure of the $\mathrm{K}_{\mathrm{ATP}}$ channel, causing depolarisation of the membrane potential. Inhibition of the voltage-gated potassium $(\mathrm{Kv})$ channel through a PKA-dependent phosphorylation leads to prolongation of the action potential duration. On depolarisation, the voltage-dependent L-type calcium channel (L-type $\mathrm{Ca}^{2+}$ ) opens and calcium flows into the cells. The PKA-dependent phosphorylation also activates the L-type calcium channel. This calcium influx into the cell causes calcium mobilisation from the endoplasmic reticulum through PKA- and EPAC2-dependent mechanisms, which serves as a significant source for increasing intracellular calcium concentration $\left(\left[\mathrm{Ca}^{2+}\right]_{\mathrm{i}}\right)$. The increase in intracellular calcium levels finally causes release of preformed insulin granules into the circulation. Furthermore, PKA mediates expression of the insulin gene as well as of GLP-1R and GIPR by activation of the WNT signalling pathway via phosphorylation of $\beta$-catenin ( $\beta$-cat.) and subsequent interaction of $\beta$-catenin with transcription factors, such as TCF7L2. WFS1 (Wolframin) has recently been identified as a component of the unfolded protein response in the endoplasmic reticulum [79], whereas $K C N Q 1$ is ubiquitously expressed in epithelial cells, including the small intestine [86] and appears to be involved in hormone and electrolyte transport processes [88]. Proteins encoded by recently identified type 2 diabetes risk loci with a potential impact on incretin secretion and action are highlighted by the boxes surrounded by solid black lines of TCF7L2 attenuated glucose-induced and cytokine-induced islet apoptosis and impaired function, confirming the important role of TCF7L2 in beta cell survival and beta cell proliferation as well as in glucose-stimulated and incretinstimulated insulin secretion [51]. Together, these studies point towards a role for TCF7L2 as the major effector of the canonical WNT signalling pathway in the pathogenesis of type 2 diabetes.

In agreement with these in vitro data, genetic variants in TCF7L2 were identified to associate with an increased risk of type 2 diabetes in humans [53-55], with impaired insulin secretion as a potential link [29, 54, 56, 57]. Two recent studies investigating the underlying mechanisms of altered insulin secretion in TCF7L2 risk allele carriers provided evidence for an involvement of TCF7L2 genetic variants (rs7903146 and rs12255372) in incretin-induced insulin secretion by comparison of OGTT and IVGTT data [50, 58] as well as by hyperglycaemic clamp combined with GLP-1 infusion, without affecting plasma GLP-1 levels [50, 58]. The lower incretin effect on insulin secretion despite similar GIP and GLP-1 responses to oral glucose in risk allele carriers was also confirmed by two recent studies [59, 60]. In agreement with these findings, knockdown of TCF7L2 in human and murine islets have demonstrated a role for the transcription factor in incretin signalling [51]. Pilgaard et al. found elevated endogenous glucose production at fasting 
Table 1 Effects of single nucleotide polymorphisms in confirmed type 2 diabetes genes on incretin action and incretin secretion

\begin{tabular}{|c|c|c|c|c|}
\hline Gene & Chr. & $\begin{array}{l}\text { Relevant tissue } \\
\text { expression }\end{array}$ & Variants (approximate RAF) & Risk allele effects \\
\hline$T C F 7 L 2$ & 10 & Pancreas & $\begin{array}{l}\text { rs7903146 }(30 \%), \text { rs } 12255372(30 \%) \\
\quad \text { rs7901695 }(30 \%)\end{array}$ & Incretin (GLP-1)-stimulated insulin secretion $\downarrow$ \\
\hline GIPR & 19 & Pancreas & rs10423928 (20\%) & Incretin (GIP)-stimulated insulin secretion $\downarrow$ \\
\hline WFS1 & 4 & Pancreas & rs10010131 (60\%) & Incretin (GLP-1)-stimulated insulin secretion $\downarrow$ \\
\hline$K C N Q 1$ & 11 & Pancreas, intestine & rs2237892 $(90 \%)$, rs151290 $(80 \%)$ & Incretin secretion $\downarrow$ \\
\hline
\end{tabular}

Chr., chromosome; RAF, risk allele frequency

conditions and during a euglycaemic-hyperinsulinaemic clamp despite diminished plasma glucagon levels in participants carrying the risk allele [60]. The authors interpreted these conflicting results as either a more direct role of TCF7L2 in the regulation of hepatic glucose homeostasis, such as modulation of expression of the gene encoding glucagon in pancreatic alpha cells [45], or as an indirect influence on hepatic glucose balance via the central nervous system. The latter assumption would be in agreement with a previous study showing that in the presence of hyperglycaemia intracerebroventricular application of the GLP-1 agonist exendin-4 resulted not only in a fourfold rise in insulin secretion, but also in increased liver glycogen storage [61].

TCF7L2 variants affect incretin actions, with alterations of the WNT signalling pathway as a potential underlying mechanism

Very recently the variant rs10423928 in the GIPR (gastric inhibitory polypeptide receptor; OMIM entry no. 137241) locus was found to associate with increased $2 \mathrm{~h}$ glucose levels during an OGTT, decreased insulin secretion, and diminished incretin effect [62]. Activation of the seventransmembrane GIPR by GIP requires interaction of the $\mathrm{N}$-terminal moiety of GIP with determinant residues within the transmembrane helices of GIPR [63]. GIPR is produced widely, but in particular is found on pancreatic beta cells. The physiological and pharmacological regulation of GIPR production is modulated by peroxisome proliferatoractivated receptor gamma signalling [64]. In different animal models, functional knockout of the Gipr gene resulted in impaired glucose tolerance with altered early insulin response after oral glucose load, whereas glucose tolerance and pancreatic beta cell function were normal following an intraperitoneal or intravenous glucose challenge $[65,66]$. In line with these findings, in different rat models of diabetes, GIPR agonist treatment exhibited beta cell anti-apoptotic actions leading to improvement of beta cell function and glycaemic control [67].

At present, the function of the intron-located GIPR variant rs10423928, which associated with indices of glucose intolerance and impaired beta cell function, remains elusive. However, it is worth noting that this single nucleotide polymorphism (SNP) is in strong linkage disequilibrium with the GIPR variant rs 1800437 , a missense mutation that results in substitution of glutamic acid by glutamine at codon 354 (E354Q). In glucose-tolerant patients homozygous for the Gln354 variant, serum C-peptide concentrations in fasting conditions and $30 \mathrm{~min}$ after an oral glucose challenge were significantly diminished compared with concentrations in wild-type carriers [68]. However, while neither in the study by Almind et al. [68] nor in two other small case-control studies of type 2 diabetes [69, 70], was an association between genetic variation in GIPR and risk for type 2 diabetes observed, in a recent meta-analysis comprising about 19,000 individuals with diabetes and more than 38,000 individuals without diabetes, the rs10423928 A allele was nominally associated with a moderate type 2 diabetes risk (OR 1.07, 95\% CI 1.03-1.12) [62].

The impact of polymorphisms in GIPR on type 2 diabetes risk and diminished incretin action is supported by its function in beta cell regulation

In light of the rather well-defined role of TCF7L2 and GIPR in the regulation of incretin actions, it appears plausible that genetic variants in these loci confer pancreatic beta cell dysfunction and increased risk for type 2 diabetes by alteration of incretin-dependent signalling pathways. In contrast, only limited data are available on the association of other type 2 diabetes risk loci, such as WFS1 and KCNQ1, with impaired incretin secretion or action. Besides, the underlying pathophysiological mechanisms by which variants within these loci contribute to alterations in the incretin system are not understood. 
In a recent hyperglycaemic clamp study combined with GLP-1 infusion, we found the variant rs10010131 in the confirmed diabetes risk gene WFS1 (Wolfram syndrome 1 [wolframin]; OMIM entry no. 606201) to be associated with impaired insulin secretion after GLP-1 administration [71] in humans. A similarly powered study confirmed reduced GLP-1 induced insulin secretion in carriers of the diabetes risk alleles [72]. WFS1 encodes an 890-amino-acid transmembrane polypeptide that is found ubiquitously, particularly in pancreatic islets and specific neurons, and is predominantly localised in the endoplasmic reticulum [73]. Mutations in the WFS1 gene cause the rare autosomal recessive neurodegenerative disorder Wolfram syndrome. In light of its clinical presentation with diabetes insipidus, young-onset non-immune insulin-dependent diabetes mellitus, optic atrophy and deafness, Wolfram syndrome is also known by the acronym DIDMOAD. In a mouse model, $W f_{s} 1$ gene knockout resulted in glucose intolerance and overt diabetes as the result of enhanced beta cell endoplasmic reticulum stress, diminished beta cell proliferation, progressive apoptotic beta cell loss and, consequently, impaired insulin secretion [74-76]. Though the exact function of wolframin is unknown, a very recent study indicated its involvement in the development of the pancreas [77]. Furthermore, based on its localisation in the pancreatic endoplasmic reticulum, a key site for insulin biosynthesis and the folding of newly synthesised proinsulin [78], polymorphisms in the WFS1 gene may alter the endoplasmic reticulum homeostasis and so impair beta cell function. This assumption would be in agreement with the recent identification of WFS1 as a component of the unfolded protein response [79]. The unfolded protein response has a key function in maintaining homeostasis of the pancreatic endoplasmic reticulum by modulating the capacity and quality of the endoplasmic reticulum protein-folding machinery to prevent the accumulation of unfolded or misfolded proteins [80]. However, impairment of the GLP-1 response may not only result in a diminished postprandial insulin secretion, but also in altered stimulation of beta cell growth and beta cell differentiation [41].

The association between WFSI variants and impaired incretin action may result from alterations of endoplasmic reticulum homeostasis and, consequently, beta cell dysfunction

Confirmed type 2 diabetes risk variants in KCNQ1 (OMIM entry no. 607542) were found to associate with insulin secretion after an OGTT [81-84] but not after an IVGTT [82]. None of these SNPs affected GLP-1-induced insulin secretion. However, one variant, rs151290, was associated with glucose-stimulated GIP and GLP-1 increase [82] in our recent study. The KCNQ1 gene encodes potassium voltage-gated channel, KQT-like subfamily, member 1 (KCNQ1), which plays an important role in controlling the ventricular repolarisation process. Mutations in $K C N Q 1$ have initially been associated with inherited cardiac disorders, such as long QT syndrome and familial atrial fibrillation. The long QT syndrome may occur in a recessive form, which is associated with deafness (Jervell and Lange-Nielsen syndrome) or in an autosomal dominant variant not associated with deafness (Romano-Ward syndrome) [85]. In addition to heart and cochlea, KCNQ1 is ubiquitously expressed in epithelial cells, including the exocrine and endocrine pancreas as well as the small intestine [86]. KCNQ1 was shown to be expressed in insulin-secreting INS-1 cells and inhibition of this potassium channel by the sulfonamide analogue 293B was found to enhance tolbutamide-induced insulin secretion [87]. In the gastrointestinal tract, KCNQ1 appears to be involved in hormone and electrolyte transport processes [88]. Though an involvement of KCNQ1 has not been shown for incretin secretion, in light of the ubiquitous expression of KCNQ1 in epithelial cells, one could speculate that genetic variants in $K C N Q 1$ may alter the effectiveness of the incretin transport machinery in the gastrointestinal tract.

Variants in $K C N Q 1$ affect glucose-induced incretin hormone release, with altered incretin transport machinery in the gastrointestinal tract as a potential explanation

Gene variants in two additional diabetes risk loci, THADA and MTNR1B, were found to be associated with altered insulin response towards GLP-1 treatment [72]. SNPs within the THADA locus associated with diminished insulin secretion following GLP-1 treatment, whereas variants within the MTNRIB locus associated with increased insulin secretion after GLP-1 stimulation. However, the associations between THADA and MTNRIB gene variants and altered pancreatic beta cell function were not specific for GLP-1 treatment but were also observed following arginine stimulation. Furthermore, the association between the risk allele of the MTNR1B SNP rs10830963 and increased insulin responses towards GLP-1 and arginine stimulation, despite a diminished insulin response to oral glucose during an OGTT [72], was surprising because incretins such as GLP-1 are known to mediate, at least in part, the insulin secretion after oral intake of glucose. Therefore, confirmation in other cohorts is important to rule out false-positive findings, before drawing any further conclusions. 
It is worth mentioning that additional known diabetes risk variants might affect incretin secretion and incretin function. Given that the effect sizes of diabetes risk alleles are often small [89], associations may have been missed by the recent studies of limited sample sizes and may be identified only by meta-analysis or large well-designed studies.

\section{Conclusions}

Recent genome-wide association studies identified several new type 2 diabetes risk loci. The majority of these risk loci appear to increase the risk of developing type 2 diabetes through alteration of pancreatic beta cell homeostasis. Though the molecular mechanisms by which the diabetes risk alleles contribute to beta cell dysfunction are not understood, in addition to glucose-induced insulin secretion and proinsulin conversion, incretin action or insulin secretion may be altered. Variants in TCF7L2, GIPR, and WFS1 were found to be associated with incretin action and variants in $K C N Q 1$ were associated with incretin secretion. Although the known physiological actions of the transcription factor TCF7L2 and the seven-transmembrane GIPR clearly indicate a pathophysiological link between genetic variation in the TCF7L2 and the GIPR loci and attenuation of incretin susceptibility, the potential underlying mechanisms by which variants in WFS1 and KCNQ1 contribute to impairments of incretin-dependent pathways still have to be identified.

In recent years, it has become evident that genetic variants in several diabetes risk genes may predict treatment outcome of glucose-lowering drugs. Response to thiazolidinedione therapy has been associated with $P P A R G$ (peroxisome proliferator-activated receptor-gamma) variation [90, 91], though not by all studies [92-94]. Literature on the impact of the $K C N J 11$ risk variant $\mathrm{E} 23 \mathrm{~K}$ on treatment response to sulfonylureas is similarly controversial. Whereas E23K associated with an increased risk of secondary failure to sulfonylureas in patients with type 2 diabetes [95], a lack of protection by metformin [96], and diminished repaglinide efficacy [97], in another study, the $K C N J 11$ risk variant did not affect response to sulfonylurea therapy [98]. Data on the association between SNPs in TCF7L2 and treatment outcome appears to be more consistent. The TCF7L2 variants have been reported to influence disease severity and therapeutic control [99], including lifestyle intervention [54], response to sulfonylureas [100] and repaglinide efficacy [97].

In light of the potential impact of a certain genetic background on treatment response towards glucose-lowering drugs, elucidation of the involvement of the type 2 diabetes risk genes with impact on incretin signals in alterations of the entero-insular axis appears to be highly relevant, as it could open novel treatment options. Though possible interactions between these type 2 diabetes risk loci with impact on incretin signals and insulin secretagogues, incretin mimetics, or dipeptidyl peptidase-4 inhibitors have, so far, not been studied, defective glucose-stimulated insulin secretion by pancreatic beta cells may be alleviated with GLP-1 analogues and dipeptidyl peptidase- 4 inhibitors in risk allele carriers.

Acknowledgement This review was supported by a grant from the German Research Foundation (no. Fr 1561/5-1).

Duality of interest The authors declare that there is no duality of interest associated with this manuscript.

\section{References}

1. Wild S, Roglic G, Green A, Sicree R, King H (2004) Global prevalence of diabetes: estimates for the year 2000 and projections for 2030. Diabetes Care 27:1047-1053

2. Kahn SE (2003) The relative contributions of insulin resistance and beta-cell dysfunction to the pathophysiology of type 2 diabetes. Diabetologia 46:3-19

3. Lieberman LS (2003) Dietary, evolutionary, and modernizing influences on the prevalence of type 2 diabetes. Annu Rev Nutr 23:345-377

4. Sladek R, Rocheleau G, Rung J et al (2007) A genome-wide association study identifies novel risk loci for type 2 diabetes. Nature 445:881-885

5. Saxena R, Voight BF, Lyssenko V et al (2007) Genome-wide association analysis identifies loci for type 2 diabetes and triglyceride levels. Science 316:1331-1336

6. Zeggini E, Weedon MN, Lindgren CM et al (2007) Replication of genome-wide association signals in UK samples reveals risk loci for type 2 diabetes. Science 316:1336-1341

7. Scott LJ, Mohlke KL, Bonnycastle LL et al (2007) A genomewide association study of type 2 diabetes in Finns detects multiple susceptibility variants. Science $316: 1341-1345$

8. Steinthorsdottir V, Thorleifsson G, Reynisdottir I et al (2007) A variant in CDKAL1 influences insulin response and risk of type 2 diabetes. Nat Genet 39:770-775

9. Frayling TM, Timpson NJ, Weedon MN et al (2007) A common variant in the FTO gene is associated with body mass index and predisposes to childhood and adult obesity. Science 316:889-894

10. Gudmundsson J, Sulem P, Steinthorsdottir V et al (2007) Two variants on chromosome 17 confer prostate cancer risk, and the one in TCF2 protects against type 2 diabetes. Nat Genet 39:977983

11. Sandhu MS, Weedon MN, Fawcett KA et al (2007) Common variants in WFS1 confer risk of type 2 diabetes. Nat Genet 39:951-953

12. Zeggini E, Scott LJ, Saxena R et al (2008) Meta-analysis of genome-wide association data and large-scale replication identifies additional susceptibility loci for type 2 diabetes. Nat Genet 40:638-645

13. Unoki H, Takahashi A, Kawaguchi T et al (2008) SNPs in KCNQ1 are associated with susceptibility to type 2 diabetes in East Asian and European populations. Nat Genet 40:1098-1102

14. Yasuda K, Miyake K, Horikawa Y et al (2008) Variants in KCNQ1 are associated with susceptibility to type 2 diabetes mellitus. Nat Genet 40:1092-1097

15. Prokopenko I, Langenberg C, Florez JC et al (2009) Variants in MTNR1B influence fasting glucose levels. Nat Genet 41:77-81 
16. Staiger H, Stancakova A, Zilinskaite J et al (2008) A candidate type 2 diabetes polymorphism near the HHEX locus affects acute glucose-stimulated insulin release in European populations: results from the EUGENE2 study. Diabetes 57:514-517

17. Staiger H, Machicao F, Stefan N et al (2007) Polymorphisms within novel risk loci for type 2 diabetes determine beta-cell function. PLoS One 2:e832

18. Moore AF, Jablonski KA, McAteer JB et al (2008) Extension of type 2 diabetes genome-wide association scan results in the diabetes prevention program. Diabetes 57:2503-2510

19. Grarup N, Rose CS, Andersson EA et al (2007) Studies of association of variants near the HHEX, CDKN2A/B, and IGF2BP2 genes with type 2 diabetes and impaired insulin release in 10, 705 Danish subjects: validation and extension of genome-wide association studies. Diabetes 56:3105-3111

20. Pascoe L, Tura A, Patel SK et al (2007) Common variants of the novel type 2 diabetes genes CDKAL1 and HHEX/IDE are associated with decreased pancreatic beta-cell function. Diabetes 56:3101-3104

21. Kirchhoff K, Machicao F, Haupt A et al (2008) Polymorphisms in the TCF7L2, CDKAL1 and SLC30A8 genes are associated with impaired proinsulin conversion. Diabetologia 51:597-601

22. Rong R, Hanson RL, Ortiz D et al (2009) Association analysis of variation in/near FTO, CDKAL1, SLC30A8, HHEX, EXT2, IGF2BP2, LOC387761, and CDKN2B with type 2 diabetes and related quantitative traits in Pima Indians. Diabetes 58:478-488

23. Palmer ND, Goodarzi MO, Langefeld CD et al (2008) Quantitative trait analysis of type 2 diabetes susceptibility loci identified from whole genome association studies in the Insulin Resistance Atherosclerosis Family Study. Diabetes 57:10931100

24. Groenewoud MJ, Dekker JM, Fritsche A et al (2008) Variants of CDKAL1 and IGF2BP2 affect first-phase insulin secretion during hyperglycaemic clamps. Diabetologia 51:1659-1663

25. Stancakova A, Pihlajamaki J, Kuusisto J et al (2008) Singlenucleotide polymorphism rs7754840 of CDKAL1 is associated with impaired insulin secretion in nondiabetic offspring of type 2 diabetic subjects and in a large sample of men with normal glucose tolerance. J Clin Endocrinol Metab 93:1924-1930

26. Pascoe L, Frayling TM, Weedon MN et al (2008) Beta cell glucose sensitivity is decreased by $39 \%$ in non-diabetic individuals carrying multiple diabetes-risk alleles compared with those with no risk alleles. Diabetologia 51:1989-1992

27. Palmer ND, Lehtinen AB, Langefeld CD et al (2008) Association of TCF7L2 gene polymorphisms with reduced acute insulin response in Hispanic Americans. J Clin Endocrinol Metab 93:304-309

28. Munoz J, Lok KH, Gower BA et al (2006) Polymorphism in the transcription factor 7-like 2 (TCF7L2) gene is associated with reduced insulin secretion in nondiabetic women. Diabetes 55:3630-3634

29. Saxena R, Gianniny L, Burtt NP et al (2006) Common single nucleotide polymorphisms in TCF7L2 are reproducibly associated with type 2 diabetes and reduce the insulin response to glucose in nondiabetic individuals. Diabetes 55:2890-2895

30. Lyssenko V, Nagorny CL, Erdos MR et al (2009) Common variant in MTNR1B associated with increased risk of type 2 diabetes and impaired early insulin secretion. Nat Genet 41:8288

31. Staiger H, Machicao F, Kantartzis K et al (2008) Novel metaanalysis-derived type 2 diabetes risk loci do not determine prediabetic phenotypes. PLoS One 3:e3019

32. Staiger H, Machicao F, Schäfer SA et al (2008) Polymorphisms within the novel type 2 diabetes risk locus MTNR1B determine beta-cell function. PLoS One 3:e3962
33. Grarup N, Andersen G, Krarup NT et al (2008) Association testing of novel type 2 diabetes risk alleles in the JAZF1, CDC123/CAMK1D, TSPAN8, THADA, ADAMTS9, and $\mathrm{NOTCH} 2$ loci with insulin release, insulin sensitivity, and obesity in a population-based sample of 4,516 glucose-tolerant middle-aged Danes. Diabetes 57:2534-2540

34. Nielsen EM, Hansen L, Carstensen B et al (2003) The E23K variant of Kir6.2 associates with impaired post-OGTT serum insulin response and increased risk of type 2 diabetes. Diabetes 52:573-577

35. Sparso T, Andersen G, Albrechtsen A et al (2008) Impact of polymorphisms in WFS1 on prediabetic phenotypes in a population-based sample of middle-aged people with normal and abnormal glucose regulation. Diabetologia 51:1646-1652

36. Florez JC, Jablonski KA, McAteer J et al (2008) Testing of diabetes-associated WFS1 polymorphisms in the Diabetes Prevention Program. Diabetologia 51:451-457

37. Wegner L, Hussain MS, Pilgaard K et al (2008) Impact of TCF7L2 rs7903146 on insulin secretion and action in young and elderly Danish twins. J Clin Endocrinol Metab 93:4013-4019

38. Gonzalez-Sanchez JL, Martinez-Larrad MT, Fernandez-Perez C, Kubaszek A, Laakso M, Serrano-Rios M (2003) K121Q PC-1 gene polymorphism is not associated with insulin resistance in a Spanish population. Obes Res 11:603-605

39. Loos RJ, Franks PW, Francis RW et al (2007) TCF7L2 polymorphisms modulate proinsulin levels and beta-cell function in a British Europid population. Diabetes 56:1943-1947

40. Stolerman ES, Manning AK, McAteer JB et al (2009) TCF7L2 variants are associated with increased proinsulin/insulin ratios but not obesity traits in the Framingham Heart Study. Diabetologia 52:614-620

41. Holst JJ, Vilsboll T, Deacon CF (2009) The incretin system and its role in type 2 diabetes mellitus. Mol Cell Endocrinol 297:127-136

42. Meier JJ, Nauck MA (2010) Is the diminished incretin effect in type 2 diabetes just an epi-phenomenon of impaired beta-cell function? Diabetes 59:1117-1125

43. Jin T (2008) The WNT signalling pathway and diabetes mellitus. Diabetologia 51:1771-1780

44. Figeac F, Uzan B, Faro M, Chelali N, Portha B, Movassat J (2010) Neonatal growth and regeneration of $\beta$ cells are regulated by the Wnt $/ \beta$-catenin signaling in normal and diabetic rats. Am J Physiol Endocrinol Metab 298:E245-E256

45. Jin T (2008) Mechanisms underlying proglucagon gene expression. J Endocrinol 198:17-28

46. Liu Z, Habener JF (2008) Glucagon-like peptide-1 activation of TCF7L2-dependent Wnt signaling enhances pancreatic beta cell proliferation. J Biol Chem 283:8723-8735

47. Bordonaro M (2009) Role of Wnt signaling in the development of type 2 diabetes. Vitam Horm 80:563-581

48. Loder MK, da Silva XG, McDonald A, Rutter GA (2008) TCF7L2 controls insulin gene expression and insulin secretion in mature pancreatic beta-cells. Biochem Soc Trans $36: 357-359$

49. Shu L, Matveyenko AV, Kerr-Conte J, Cho JH, McIntosh CH, Maedler K (2009) Decreased TCF7L2 protein levels in type 2 diabetes mellitus correlate with downregulation of GIP- and GLP-1 receptors and impaired beta-cell function. Hum Mol Genet 18:2388-2399

50. Lyssenko V, Lupi R, Marchetti P et al (2007) Mechanisms by which common variants in the TCF7L2 gene increase risk of type 2 diabetes. J Clin Invest 117:2155-2163

51. Shu L, Sauter NS, Schulthess FT, Matveyenko AV, Oberholzer J, Maedler K (2008) Transcription factor 7-like 2 regulates betacell survival and function in human pancreatic islets. Diabetes $57: 645-653$ 
52. da Silva XG, Loder MK, McDonald A et al (2009) TCF7L2 regulates late events in insulin secretion from pancreatic islet beta-cells. Diabetes 58:894-905

53. Grant SF, Thorleifsson G, Reynisdottir I et al (2006) Variant of transcription factor 7-like 2 (TCF7L2) gene confers risk of type 2 diabetes. Nat Genet 38:320-323

54. Florez JC, Jablonski KA, Bayley N et al (2006) TCF7L2 polymorphisms and progression to diabetes in the Diabetes Prevention Program. N Engl J Med 355:241-250

55. Helgason A, Palsson S, Thorleifsson G et al (2007) Refining the impact of TCF7L2 gene variants on type 2 diabetes and adaptive evolution. Nat Genet 39:218-225

56. Scott LJ, Bonnycastle LL, Willer CJ et al (2006) Association of transcription factor 7-like 2 (TCF7L2) variants with type 2 diabetes in a Finnish sample. Diabetes 55:2649-2653

57. Damcott CM, Pollin TI, Reinhart LJ et al (2006) Polymorphisms in the transcription factor 7-like 2 (TCF7L2) gene are associated with type 2 diabetes in the Amish: replication and evidence for a role in both insulin secretion and insulin resistance. Diabetes 55:2654-2659

58. Schäfer SA, Tschritter O, Machicao F et al (2007) Impaired glucagon-like peptide-1-induced insulin secretion in carriers of transcription factor 7-like 2 (TCF7L2) gene polymorphisms. Diabetologia 50:2443-2450

59. Villareal DT, Robertson H, Bell GI et al (2010) TCF7L2 variant rs7903146 affects the risk of type 2 diabetes by modulating incretin action. Diabetes 59:479-485

60. Pilgaard K, Jensen CB, Schou JH et al (2009) The T allele of rs7903146 TCF7L2 is associated with impaired insulinotropic action of incretin hormones, reduced $24 \mathrm{~h}$ profiles of plasma insulin and glucagon, and increased hepatic glucose production in young healthy men. Diabetologia 52:1298-1307

61. Knauf C, Cani PD, Perrin C et al (2005) Brain glucagon-like peptide-1 increases insulin secretion and muscle insulin resistance to favor hepatic glycogen storage. J Clin Invest 115:3554-3563

62. Saxena R, Hivert MF, Langenberg C et al (2010) Genetic variation in GIPR influences the glucose and insulin responses to an oral glucose challenge. Nat Genet 42:142-148

63. Yaqub T, Tikhonova IG, Lattig J et al (2010) Identification of determinants of glucose-dependent insulinotropic polypeptide receptor that interact with $\mathrm{N}$-terminal biologically active region of the natural ligand. Mol Pharmacol 77:547-558

64. Gupta D, Peshavaria M, Monga N, Jetton TL, Leahy JL (2010) Physiologic and pharmacologic modulation of GIP receptor expression in ss-cells by PPARgamma signaling: possible mechanism for the GIP resistance in type 2 diabetes. Diabetes 59:1445-1450

65. Miyawaki K, Yamada Y, Yano H et al (1999) Glucose intolerance caused by a defect in the entero-insular axis: a study in gastric inhibitory polypeptide receptor knockout mice. Proc Natl Acad Sci USA 96:14843-14847

66. Renner S, Fehlings C, Herbach N et al (2010) Glucose intolerance and reduced proliferation of pancreatic beta-cells in transgenic pigs with impaired glucose-dependent insulinotropic polypeptide function. Diabetes 59:1228-1238

67. Widenmaier SB, Kim SJ, Yang GK et al (2010) A GIP receptor agonist exhibits beta-cell anti-apoptotic actions in rat models of diabetes resulting in improved beta-cell function and glycemic control. PLoS One 5:e9590

68. Almind K, Ambye L, Urhammer SA et al (1998) Discovery of amino acid variants in the human glucose-dependent insulinotropic polypeptide (GIP) receptor: the impact on the pancreatic beta cell responses and functional expression studies in Chinese hamster fibroblast cells. Diabetologia 41:1194-1198

69. Kubota A, Yamada Y, Hayami T et al (1996) Identification of two missense mutations in the GIP receptor gene: a functional study and association analysis with NIDDM: no evidence of association with Japanese NIDDM subjects. Diabetes 45:1701-1705

70. Nitz I, Fisher E, Weikert C et al (2007) Association analyses of GIP and GIPR polymorphisms with traits of the metabolic syndrome. Mol Nutr Food Res 51:1046-1052

71. Schäfer SA, Müssig K, Staiger H et al (2009) A common genetic variant in WFS1 determines impaired glucagon-like peptide-1induced insulin secretion. Diabetologia 52:1075-1082

72. Simonis-Bik AM, Nijpels G, van Haeften TW et al (2010) Gene variants in the novel type 2 diabetes loci CDC123/CAMK1D, THADA, ADAMTS9, BCL11A, and MTNR1B affect different aspects of pancreatic beta-cell function. Diabetes 59:293-301

73. Takeda K, Inoue H, Tanizawa Y et al (2001) WFS1 (Wolfram syndrome 1) gene product: predominant subcellular localization to endoplasmic reticulum in cultured cells and neuronal expression in rat brain. Hum Mol Genet 10:477-484

74. Ishihara H, Takeda S, Tamura A et al (2004) Disruption of the WFS1 gene in mice causes progressive beta-cell loss and impaired stimulus-secretion coupling in insulin secretion. Hum Mol Genet 13:1159-1170

75. Riggs AC, Bernal-Mizrachi E, Ohsugi M et al (2005) Mice conditionally lacking the Wolfram gene in pancreatic islet beta cells exhibit diabetes as a result of enhanced endoplasmic reticulum stress and apoptosis. Diabetologia 48:2313-2321

76. Yamada T, Ishihara H, Tamura A et al (2006) WFS1-deficiency increases endoplasmic reticulum stress, impairs cell cycle progression and triggers the apoptotic pathway specifically in pancreatic beta-cells. Hum Mol Genet 15:1600-1609

77. Xu R, Xia B, Geng J et al (2009) Expression and localization of Wolfram syndrome 1 gene in the developing rat pancreas. World J Gastroenterol 15:5425-5431

78. Scheuner D, Kaufman RJ (2008) The unfolded protein response: a pathway that links insulin demand with beta-cell failure and diabetes. Endocr Rev 29:317-333

79. Fonseca SG, Fukuma M, Lipson KL et al (2005) WFS1 is a novel component of the unfolded protein response and maintains homeostasis of the endoplasmic reticulum in pancreatic betacells. J Biol Chem 280:39609-39615

80. Marciniak SJ, Ron D (2006) Endoplasmic reticulum stress signaling in disease. Physiol Rev 86:1133-1149

81. Jonsson A, Isomaa B, Tuomi $\mathrm{T}$ et al (2009) A variant in the KCNQ1 gene predicts future type 2 diabetes and mediates impaired insulin secretion. Diabetes 58:2409-2413

82. Müssig K, Staiger H, Machicao F et al (2009) Association of type 2 diabetes candidate polymorphisms in KCNQ1 with incretin and insulin secretion. Diabetes 58:1715-1720

83. Holmkvist J, Banasik K, Andersen G et al (2009) The type 2 diabetes associated minor allele of rs $2237895 \mathrm{KCNQ} 1$ associates with reduced insulin release following an oral glucose load. PLoS One 4:e5872

84. Tan JT, Nurbaya S, Gardner D, Ye S, Tai ES, Ng DP (2009) Genetic variation in KCNQ1 associates with fasting glucose and beta-cell function: a study of 3,734 subjects comprising three ethnicities living in Singapore. Diabetes 58:1445-1449

85. Towbin JA, Vatta M (2001) Molecular biology and the prolonged QT syndromes. Am J Med 110:385-398

86. Thevenod F (2002) Ion channels in secretory granules of the pancreas and their role in exocytosis and release of secretory proteins. Am J Physiol Cell Physiol 283:C651-C672

87. Ullrich S, Su J, Ranta F et al (2005) Effects of I(Ks) channel inhibitors in insulin-secreting INS-1 cells. Pflugers Arch 451:428-436

88. Vallon V, Grahammer F, Volk1 H et al (2005) KCNQ1-dependent transport in renal and gastrointestinal epithelia. Proc Natl Acad Sci USA 102:17864-17869

89. Dupuis J, Langenberg C, Prokopenko I et al (2010) New genetic loci implicated in fasting glucose homeostasis and their impact on type 2 diabetes risk. Nat Genet 42:105-116 
90. Wolford JK, Yeatts KA, Dhanjal SK et al (2005) Sequence variation in PPARG may underlie differential response to troglitazone. Diabetes 54:3319-3325

91. Kang ES, Park SY, Kim HJ et al (2005) Effects of Pro12Ala polymorphism of peroxisome proliferator-activated receptor gamma2 gene on rosiglitazone response in type 2 diabetes. Clin Pharmacol Ther 78:202-208

92. Blüher M, Lubben G, Paschke R (2003) Analysis of the relationship between the Pro12Ala variant in the PPARgamma2 gene and the response rate to therapy with pioglitazone in patients with type 2 diabetes. Diabetes Care 26:825-831

93. Snitker S, Watanabe RM, Ani I et al (2004) Changes in insulin sensitivity in response to troglitazone do not differ between subjects with and without the common, functional Pro12Ala peroxisome proliferator-activated receptor-gamma2 gene variant: results from the Troglitazone in Prevention of Diabetes (TRIPOD) study. Diabetes Care 27:1365-1368

94. Florez JC, Jablonski KA, Sun MW et al (2007) Effects of the type 2 diabetes-associated PPARG P12A polymorphism on progression to diabetes and response to troglitazone. J Clin Endocrinol Metab 92:1502-1509

95. Sesti G, Laratta E, Cardellini M et al (2006) The E23K variant of KCNJ11 encoding the pancreatic beta-cell adenosine 5'-triphosphate-sensitive potassium channel subunit Kir6.2 is associated with an increased risk of secondary failure to sulfonylurea in patients with type 2 diabetes. J Clin Endocrinol Metab 91:2334 2339

96. Florez JC, Jablonski KA, Kahn SE et al (2007) Type 2 diabetesassociated missense polymorphisms KCNJ11 E23K and ABCC8 A1369S influence progression to diabetes and response to interventions in the Diabetes Prevention Program. Diabetes 56:531-536

97. Yu M, Xu XJ, Yin JY et al (2010) KCNJ11 Lys23Glu and TCF7L2 rs290487(C/T) polymorphisms affect therapeutic efficacy of repaglinide in Chinese patients with type 2 diabetes. Clin Pharmacol Ther 87:330-335

98. Gloyn AL, Hashim Y, Ashcroft SJ, Ashfield R, Wiltshire S, Turner RC (2001) Association studies of variants in promoter and coding regions of beta-cell ATP-sensitive K-channel genes SUR1 and Kir6.2 with Type 2 diabetes mellitus (UKPDS 53). Diabet Med 18:206-212

99. Kimber CH, Doney AS, Pearson ER et al (2007) TCF7L2 in the Go-DARTS study: evidence for a gene dose effect on both diabetes susceptibility and control of glucose levels. Diabetologia 50:1186-1191

100. Pearson ER, Donnelly LA, Kimber C et al (2007) Variation in TCF7L2 influences therapeutic response to sulfonylureas: a GoDARTs study. Diabetes 56:2178-2182 